\title{
Occupational therapists' experiences of enabling people to participate in sport
}

\section{Introduction}

Evidence gathered from disciplines including public health, medicine, sports science, psychology and occupational therapy highlight benefits of participating in sport. For example preventing and managing physical and mental health conditions, increasing quality of life and social participation (Creek, 2014; Public Health England, 2018; Sport England, 2017). By participating in the recommended amount of exercise per week the risk of developing long term conditions such as heart disease can be reduced by up to $40 \%$ and type 2 diabetes by $50 \%$ (Academy of Medical Royal Colleges, 2015). Despite this evidence, Public Health England [PHE] (2018) are concerned that people are becoming less active, highlighting how physical inactivity costs the UK $£ 7.4$ billion annually, with $£ 0.9$ billion of these costs falling to the National Health Service [NHS].

In response to growing demands on health and social care services there is an emphasis on communities addressing the needs of local populations to improve lives and reduce health inequalities (Department of Health, 2010). Government drives towards health promotion, well-being, and illness prevention include strategies to increase participation in sport (PHE, 2018). In 'Sporting Future: a new strategy for an active nation' (HM Government, 2015: 10), the focus is on enabling participation to achieve "physical well-being, mental well-being, individual development, social and community development and economic development". Similar strategies to increase levels of physical activity in local populations are mirrored across the globe, for example campaigns such as 'Every Body Active' in New Zealand (Sport New Zealand, 2020) and 'Get Ireland Active!' in Ireland (Healthy Ireland, 2016).

This presents opportunities for occupational therapists to enact the core philosophy of the profession, promoting occupational engagement to enhance well-being (Wilcock, 2006) by expanding their scope of practice into innovative settings and addressing social and occupational injustices experienced by those with disabilities such as inaccessible environments, stigma, attitudes, policies, limited choice of control (Whiteford, 2011). Occupational therapists could play a pivotal role promoting the benefits of sport and 
supporting engagement in participation (Royal College of Occupational Therapists, 2018). Using their unique skills, occupational therapists could enhance opportunities for participation through activity analysis, adaptations and by eliminating barriers to inclusion (Creek, 2014; Sharp, Dunford and Seddon, 2012). However, there appears little evidence to support this assertion. The overall aim of this study was therefore to gain a deeper understanding of the experiences of occupational therapists working in diverse settings who enable people to engage in sport as a therapeutic activity. For the purposes of this study, sport included a range of activities, for example incorporating physical activity into people's daily lives through meaningful activities such as walking the dog, through to team sports.

\section{Literature Review}

Occupational therapists are increasingly working outside of traditional settings to enable people to participate in sport. 'Sense Rugby', for example, is an Australian occupational therapy practice enabling children with developmental delays and conditions to participate in rugby (Sense Rugby, 2019). Similarly, 'Box Positive', set up by a UK occupational therapist, uses boxing as a therapeutic intervention for people with Parkinson's disease (Box Positive, 2019). However, there appears to be an absence of empirical research exploring these kinds of innovative practices.

Arguably, sports coaches and personal trainers are best placed to enable participation in sport because they receive sports-specific training (De Lyon, Neville and Armour, 2017). This may explain the absence of occupational therapy literature. However, in a systematic review by Stacey et al. (2010), exploring the education and training of sports coaches and personal trainers, the authors revealed concerns about the lack of evidence-based knowledge used in their training. Further evidence suggests a lack of awareness about disability and how to enhance opportunities for participation (Wareham et al., 2018). A qualitative study examining the perspectives and experiences of Paralympic coaches also revealed a need for mentoring from specialists such as occupational therapists about the complexities of disability and a need for this to be included in their training (Fairhurst, Bloom and Harvey, 2016). 
Physiotherapists support people to be physically active as part of their role (Williams, et al., 2018). The World Confederation of Physical Therapy (WCPT) hail physiotherapists as the "specialists in human activity and movement", using physical activity to promote health and improve lifestyles (WCPT, 2020). However, Lee et al. (2017) highlighted how physiotherapists are often perceived by other health professionals as being concerned with specific musculoskeletal problems or injuries and that there is a lack of understanding about its relevance within mental health teams and concern about the lack of knowledge and skills in this field. This is in contrast to occupational therapists who are dual educated in physical and mental health theories, philosophies and interventions that support their direct patient care and enable participation in sport (Hunter et al., 2017; Siegel et al., 2017; Sharp, Dunford and Seddon, 2012). However, despite this holistic approach Turner (2011) has highlighted how occupational therapy is often similarly misunderstood and there has been a historical struggle for therapists to identify and assert their unique identity in multi-professional teams. This highlights the importance of research that seeks to highlight the clear role for occupational therapists in practice settings, including emerging and innovative practice such as sports.

Literature suggests occupational therapists could play a pivotal role enabling participation in physical activity (Hunter et al., 2017; Siegel et al., 2017; Sharp, Dunford and Seddon, 2012). In a systematic review evaluating physical activity interventions for people with rheumatoid arthritis, Siegel et al. (2017) advocated for the role of occupational therapy facilitating exercise-based interventions. In a similar review Hunter et al. (2017) suggest occupational therapists are well placed to facilitate physical activity interventions in cancer rehabilitation. However, the majority of the papers reviewed in both these studies included interventions which focused on impairment or functional performance rather than occupational engagement or the experiences of the therapists.

In their literature review, Sharp, Dunford and Seddon (2012) identified a role for occupational therapists enabling children and young people to participate in adaptive physical activity. The paper explored the types of interventions occupational therapists could use in this setting; however, it does not offer an in-depth exploration of the experiences of occupational therapists working in these settings. It is therefore difficult to gain an understanding of the 
benefits, potential challenges, and associated risks of working outside traditional settings and enabling participation in sport.

Whilst literature suggests that occupational therapists may have a significant role in enabling people to participate in sport, this specialist area of practice appears to be underexplored. The aim of this study was therefore to develop further insight into the experiences of occupational therapists who work with individuals to enable their participation in sport.

\section{Method}

This study adopted a qualitative research design, based on phenomenological principles, which allowed for an in-depth exploration of occupational therapists' unique experiences of enabling others to engage in sports and how they attributed meaning to their practice. The study was located within an interpretivist paradigm with a critical realist ontology. This means the researcher acknowledges they are part of the world they are studying, and their collection and interpretation of data will be influenced by their values, experiences and assumptions (Finlay, 2006). The researcher believes that phenomena will be experienced, interpreted and understood differently by different individuals (Green and Thorogood, 2018) but that there may be commonalities that enable the reader to gain insight into what the experience of working in this area of practice may be like.

\section{$\underline{\text { Participants and recruitment }}$}

Ethical approval was procured from the University of XX Research Ethics Committee to recruit five experienced occupational therapists working outside of NHS and social care settings. Small sample sizes are recommended to remain focused on gaining an in-depth understanding of each participant's experience whilst credibly demonstrating patterns across the data set (Braun and Clark, 2013).

An email, including participant information and a consent form, was sent out by a lecturer to the University's database of occupational therapists working in diverse settings. Additionally, the researcher obtained permission from the administrators of various social media pages of 
sport organisations to share information about the study on their community pages. The first five occupational therapists who expressed interest participated in the study. All participants were qualified occupational therapists working in non-traditional settings (Table 1).

Table 1: Participants.

\begin{tabular}{|l|l|}
\hline $\begin{array}{l}\text { Participant } \\
\text { (pseudonyms) }\end{array}$ & Work location \\
\hline Kim & $\begin{array}{l}\text { A social enterprise offering occupational } \\
\text { therapy in leisure centres }\end{array}$ \\
\hline Lisa & A hostel for asylum seekers \\
\hline Patricia & $\begin{array}{l}\text { A social enterprise offering occupational } \\
\text { therapy in leisure centres }\end{array}$ \\
\hline Sam & Private practice offering personal training \\
\hline Shaneen & Military rehabilitation centre. \\
\hline
\end{tabular}

$\underline{\text { Data collection }}$

As participants were drawn from around the UK, semi-structured interviews were undertaken by the first author via telephone or Skype. These lasted up to sixty minutes and were audio recorded for transcription purposes, with consent from the participants. Each interview started with a broad question about the participant's experiences of facilitating sport and then prompts were used to help them provide more detailed examples of their experiences, for example:

Table 2: Example questions.

What is your experience of engaging people in sport?

How do you use your occupational therapy knowledge and skills to help you in this role? 
What are the positive aspects and challenges of working in this diverse area of practice?

This approach allowed the interview to be led by the experiences that were important and meaningful to each participant. It is the one most commonly used in qualitative health research, allowing in-depth exploration of a person's unique experience (Braun and Clark, 2013).

\section{Data Analysis}

The interviews were transcribed verbatim by the researcher and systematically analysed using Braun and Clarke's (2013) inductive approach to highlight themes and patterns of meaning in the data. Braun and Clarke (2013) describe thematic analysis as a foundational method for qualitative research and recommend six phases of thematic analysis that were used to guide the research process, as illustrated in Table 3.

Table 3: Summary of Braun and Clarke's (2013) six phases of thematic analysis.

\begin{tabular}{|l|l|}
\hline Phase 1 & $\begin{array}{l}\text { Become familiar with the data: transcribe interviews verbatim, } \\
\text { read and re-read data noting down initial ideas. }\end{array}$ \\
\hline Phase 2 & $\begin{array}{l}\text { Generate initial codes: highlight interesting and important content } \\
\text { across entire data set. }\end{array}$ \\
\hline Phase 3 & $\begin{array}{l}\text { Search for themes: identify and collate over-arching themes and } \\
\text { sub-themes from the initial codes. }\end{array}$ \\
\hline Phase 4 & $\begin{array}{l}\text { Review themes: check themes and create a thematic map of the } \\
\text { analysis. }\end{array}$ \\
\hline Phase 5 & $\begin{array}{l}\text { Define and name themes: ongoing analysis to define and generate } \\
\text { clear meanings and names for each theme. }\end{array}$ \\
\hline
\end{tabular}




\begin{tabular}{|l|l|}
\hline Phase 6 & $\begin{array}{l}\text { Produce the report: a final opportunity for analysis; select and } \\
\text { combine the analytic descriptions and data excerpts to produce a } \\
\text { coherent report of the analysis. }\end{array}$ \\
\hline
\end{tabular}

The transcripts were read and re-read by the researcher, ideas were noted down, reviewed and collated into 120 initial codes. The codes were collated into sub-themes and over-arching themes and the themes that were present across all data sets were included in the findings.

Table 4: Example codes, sub-themes and over-arching themes.

\begin{tabular}{|c|c|c|}
\hline Codes & Sub-theme & Over-arching theme \\
\hline $\begin{array}{l}\text { The environment can be a barrier to } \\
\text { participation. }\end{array}$ & Barriers to inclusion & \multirow{3}{*}{$\begin{array}{l}\text { Opportunities and } \\
\text { Challenges }\end{array}$} \\
\hline $\begin{array}{l}\text { Establishing relationships with } \\
\text { sporting organisations. }\end{array}$ & $\begin{array}{l}\text { Promoting occupational } \\
\text { therapy }\end{array}$ & \\
\hline $\begin{array}{l}\text { Challenges promoting the role of } \\
\text { occupational therapy to the general } \\
\text { public in role emerging fields. }\end{array}$ & $\begin{array}{l}\text { Challenges in diverse } \\
\text { settings }\end{array}$ & \\
\hline Grading or adapting an activity. & Needs led & \multirow[b]{2}{*}{$\begin{array}{l}\text { Occupational } \\
\text { therapy lens }\end{array}$} \\
\hline $\begin{array}{l}\text { Helping to embed physical activity } \\
\text { into their routine. }\end{array}$ & $\begin{array}{l}\text { Health prevention and } \\
\text { promotion }\end{array}$ & \\
\hline
\end{tabular}

$\underline{\text { Rigour }}$

The research was carried out as part of a Master's Degree in Occupational Therapy. The researcher became interested in use of sport as a therapeutic intervention having successfully used physical activities with children on a clinical practice placement. In order to acknowledge this interest and the researcher's personal beliefs, experiences and potential bias when interpreting and synthesising the data, a reflexive journal was kept, as literature suggests this enhances rigour in qualitative research (Finlay, 2006). This was regularly discussed with research supervisor to ensure the findings stayed true to participants' experiences. 
To further enhance trustworthiness, the research process was meticulously documented, and transcripts and emergent themes reviewed by the researcher's supervisor who was an experienced qualitative researcher. Additionally, verbatim quotations from the transcripts were used to demonstrate how the themes reflected experiences of the participants, which Noble and Smith (2015) recommend as best practice.

\section{Ethical considerations}

As recommended by Taylor and Kielhofner (2017), before giving their informed consent participants were prospectively informed about the purpose of the study, the benefits and risks of participating and information about confidentiality, anonymity and data protection, according to the General Data Protection Regulation (2018). They were informed their participation was voluntary and that they could withdraw from the study at any time. Assurance was given that identifiable information would be removed, pseudonyms would be used throughout, and data would be destroyed after 10 years.

\section{Findings}

Following data analysis, two overarching themes emerged: 'Practicing through an Occupational Therapy Lens' and 'Opportunities and Challenges for Occupational Therapists'. Each of these themes had sub-themes, illustrated in Table 5.

Table 5: Themes.

\begin{tabular}{|l|l|}
\hline Main theme & Sub-theme \\
\hline Practicing through an & $\bullet$ Underpinning practice with occupational \\
Occupational Therapy Lens & therapy philosophy \\
& $\begin{array}{l}\text { - The unique skills occupational therapists } \\
\text { bring }\end{array}$ \\
\hline $\begin{array}{l}\text { Opportunities and Challenges } \\
\text { for Occupational Therapists }\end{array}$ & $\begin{array}{l}\text { Challenges of working outside traditional } \\
\text { settings }\end{array}$ \\
\hline
\end{tabular}




\begin{tabular}{|l|l|}
\hline & $\bullet$ Barriers to inclusion for clients \\
& $\bullet$ Opportunities for the profession \\
\hline
\end{tabular}

\section{Theme 1: Practicing through an Occupational Therapy Lens}

This theme demonstrates how participants viewed their clients through an occupational therapy lens, using a holistic approach to understand their needs. Participants remained focused on occupation, using meaningful activities as a therapeutic medium, breaking down activities and addressing the occupational performance skills required in order to grade and adapt the activity and enable successful participation. It was evident that participants used their dual education in mental and physical health and core skills to address all areas of their client's lives, assessing physical, mental, environmental, cultural and social factors.

\section{Underpinning practice with occupational therapy philosophy}

When discussing the importance of engaging their clients in occupations that were meaningful or relevant to their needs, participants highlighted the link between 'doing', activity and well-being:

...in offering gym and boxercise we really saw a change in their engagement and their health and well-being as a consequence... (Sam)

Participants described addressing occupational injustices in the wider community, advocating for social inclusion and equality and drawing on occupational science concepts. Patricia for example, appeared to reflect on occupational marginalisation and social inclusion and highlighted the importance of ensuring her clients had choice and control over their occupations: 
From an occupational justice point of view, it's about offering a diversity of opportunity, not just saying that the only opportunity for people to play sport is with other disabled people.

Lisa similarly drew on the notion of occupational deprivation to highlight the impact of boredom and exclusion on mental well-being experienced by her clients whilst seeking refuge in the UK and living in temporary accommodation:

...often they say "I'm really bored and it's really causing me stress"... innately we do stuff, we are humans, we want to be engaged and when we're not allowed to that's torturous. We talk a lot about... how you think and how you feel and the more activities that you do the likelihood is that you'll feel better...

Participants discussed client-centred practice and how important it was to appreciate, and respond to, the client's unique needs:

...you have people who have a learning disability or... mental health issues or they are socially isolated... have had a stroke... lots of stuff, so then obviously the interventions... and your approach just differs massively because of the variety of people that come to the sessions... (Kim)

Similarly, Lisa identified the holistic needs of the refugees she worked with, recognising the social as well as the health benefits of participating in sport. Here she reflected on how the interventions created a sense of connection and belonging in the hostel:

...sessions not only have a positive impact on their mood and behaviour and... managing their stresses... it has an impact on their whole experience in the hostel. They say they feel much happier and feel more connected to other people and less alone.

Participants' holistic philosophy was also evident, for example, highlighting the need to consider the wider perspective of a client's life and addressing the needs, and supporting, family and carers: 
we have a dementia friendly swimming session and a gentleman and his wife came to that, he was experiencing early stages dementia and she was saying that he'd like to come down and swim and she'd like him to because at the moment he's well enough to walk there on his own and walk back and that gave her important respite, but she said she wouldn't feel happy for him to do that without her knowing that we are at the other end, has he got there okay, is he getting on alright in the changing room, in the pool and then someone seeing him off home back the other way. I think those kind of things are really important...(Patricia)

Participants described how their interventions helped nurture new social relationships and enabled clients to transfer the confidence they gained and re-establish engagement in other meaningful activities:

...we often see that people establish friendships and then they meet up and go to the cinema at the weekend... Once people start to establish those relationships through the occupation that then inevitably often leads to other occupations and other participation as people have people to do things with. (Patricia)

\section{The unique skills occupational therapists bring}

Participants highlighted how they used sport therapeutically and collaborated with clients to set meaningful occupational goals. They used their core skills to grade or modify activities or adapt the environment to enable successful participation. Sam reflected on how she motivated clients:

that's where OT comes in and our understanding around motivation, for some people physical activity will be intrinsically motivating in itself and that's fabulous... because of the market I'm aiming towards that isn't ever the case, it's about finding other ways of building on that motivation and that volition and that's got to be through looking at what's meaningful to them and their daily lives. 
Sam thought the term 'physical activity' was a barrier to some and described collaborating with a client to find out what was meaningful to her and how she could motivate her and integrate physical activity into her everyday occupations:

...when I pitch it around walking her dog and doing other meaningful activities she's able to engage in it much more regularly.

In order to make sport more accessible for people that faced barriers to participation, each participant described using their core occupational therapy skills. Patricia said sport "could be very elitist...and ...divisive" and felt it was important to think about "where we get people involved" and "grading different things, breaking things down, and thinking about peoples' environment..." to ensure successful participation. Similarly, Kim used a graded approach to break down barriers to inclusion by initially visiting a client in their own home, enabling trust and rapport to develop:

So sometimes we would bring the activity to them first, to introduce it to them, introduce ourselves to them, get them comfortable with us and slowly grade the approach.

Finding the 'just right challenge', by adapting an activity to meet their client's needs, was also recognised as important:

it's like an activity analysis, you're breaking down all the steps that are involved in playing this, or doing this activity and you're comparing it to the abilities of the person and you're just trying to identify what they might be able to do and what they might be able to cope with and slowly building it from there (Kim)

not putting them in an environment where they are likely to fail (Shaneen)

Sam and Shaneen's experience had a clear impact on awareness of occupational therapy and client needs in their organisation where, for example, they advised staff to think about 
environmental barriers from a more holistic perspective; to address psychological and sensory barriers as well as the physical:

...they tended to think of accessibility in terms of physical health whilst I would say 'look there's a lot of barriers for people with mental health disabilities in accessing this. (Sam)

[Highlighting that]...sensory overload and over stimulation is an issue... where actually busy environments and light environments and visually stimulated environments are a problem... (Shaneen)

Similarly, Patricia supported organisations to make their venues accessible to all, by raising awareness about the types of environmental barriers people may face:

they can see a clear benefit of having us around... we'll talk to them about things like if you have a black mat in the doorway, that can be a barrier to someone with dementia, they will see that as a hole...

Theme 2: Challenges and opportunities for occupational therapists

This theme highlights the challenges participants faced working outside of traditional settings and some of their clients' barriers to inclusion. The final sub-theme highlights opportunities to promote the profession and the value of their unique perspective in emerging areas of practice.

\section{Challenges of working outside traditional settings}

Kim loved the freedom of her job but sometimes felt overwhelmed by the diversity of her practice and breadth of knowledge and experience she needed to have:

...there's such a variety of people that come along, so in one way you're not particularly specialised in one thing but in another way you have experience in everything. 
Patricia highlighted the challenges of offering occupational therapy within a mainstream environment, such as accessing background history, which did not arise in traditional clinical settings. She also talked about the way her role as a therapist might be interpreted by clients when she was "just enabling people to take part" and how she needed to be mindful about promoting herself as a therapist:

A lot of our clients don't have a diagnosis, even those that do have a diagnosis don't see themselves as having a diagnosis so if things are tagged as a disability sport that's a barrier in itself because people don't identify with having a disability....but equally then if we are approaching it from a more conventional way, i.e. "I'm your therapist and I'm now doing an assessment", they will be like "woah, wait a minute why am I having therapy? It's just about me coming along to the leisure centre'.

Sam also highlighted this challenge related to professional identify and promoting her role outside of a traditional setting:

I don't think any of my clients will be able to tell you "oh Sam's professional background is occupational therapy...I think there's a challenge in how we promote our profession to the general public in these kind of role emerging fields.

\section{Barriers to inclusion for clients}

Participants were concerned about the barriers people faced to participating in sport and spoke about increasing accessibility and inclusivity. Kim reflected on the challenges of this and felt that fully inclusive sport could also be a barrier:

we might have an activity where there might be someone with... severe autism or something... and then this person might be expressing themselves in a different type of way where they are using loud noises or lots of hand gestures... sometimes people are like... no, I don't really identify with that or can't understand it or don't want to be in an activity where they feel like someone has more needs then they do. 
Patricia similarly highlighted the potential for disabled access to create a disabled apartheid:

often because of the funding arrangements of disability projects they can only accept disabled people, so it ends up being quite segregated. I feel there is the potential for disability sport to perpetuate marginalisation and segregation, we don't have disability shopping for example.

Patricia thought there was not enough diversity in staff teams in the sports sector as it appeared they only recruited the "lycra brigade". She felt this limited recognition of other people's needs who aren't 'sporty or who may have barriers to engagement':

...I think the sports sector quite obviously really tends to employ people who are very sporty, who think sport's brilliant and who think everyone should be doing more and to some extent that is great but I think those people sometimes really struggle to understand some of the issues and challenges and reservations that people who aren't so active come with.

\section{Opportunities for the profession}

By working outside traditional settings participants felt they were able to reach wider communities and those who were not accessing services because they didn't "meet the criteria for one diagnosis... and so they are just left in limbo" (Kim).

Participants felt that with the current political climate of promoting health and activity there are lots of opportunities for occupational therapists and described some they were embracing. Sam talked about the opportunities arising from General Practitioners (GPs) who were referring patients to social prescribing schemes:

GP referral schemes which massively encourage social prescribing and I'm liaising with the person who coordinates that for my geographical area... so there are opportunities that I'm currently exploring. (Sam) 
So in terms of working with GPs that would have been done as part of our outreach where we do a lot of media stuff...so any way you can think of to get in touch with people we do. (Kim)

Participants talked about collaborating and sharing their skills with wider organisations. Patricia, for example mentored sports coaches with "some of the softer skills around building rapport with someone", and ways to adapt communication if someone used signs and symbols as their main method of communication, or communicated at "a different pace". She thought these skills "were absent in the sports sector" and felt there were opportunities for occupational therapists to contribute their skills and knowledge, particularly about "grading an activity and thinking about breaking it down into certain steps..."

Patricia suggested that now was the ideal moment to form partnerships and promote the value of occupational therapy within the sports sector:

We are in quite a unique time where we've got this opportunity in terms of this national inactivity problem, we've got a sport sector and a health sector that's saying we need to get more people active and if you want a profession that understands the complex relationship between what people do and their health....tah dah... but I think it's about making sure that we stand up when we need to...

\section{Discussion}

Findings from this study add to the growing research base that has found that occupational therapists are exploring new territory, stretching the boundaries and making a difference in areas outside of traditional practice (Stickley and Hall, 2017; Wood, Fortune and McKinstry, 2013). This study demonstrates how the occupational therapist role can be distinguished from other professionals in the sports sector, and highlights their unique contribution and application of competencies, knowledge and attitudes, concerning occupation, enablement and social justice. 
By offering services outside of traditional settings the participants were able to extend their professional reach to wider communities and engage hard to reach and marginalised groups and underserved populations, including those without a diagnosis. This clearly suggests their practices are underpinned by occupational science concepts, such as Wilcock's (2006) theory of occupational justice, and are congruent with contemporary health and social care drivers, such as the World Health Organization (2018) Global Action Plan: 'more active people for a healthier new world'.

Participants believed they empowered their clients by offering choice and control over the occupations they participated in, which the Royal College of Occupational Therapists (2019) recognise as a determinant of health and wellbeing. Findings reinforce Wilcock and Hocking's (2015: p134) concept of "doing, being, becoming and belonging", suggesting that reengaging in sport activities had an impact on participant's wellbeing and sense of community. This demonstrates they were able to implement occupational therapy in a way that was congruent with the core philosophy of the profession. These findings are consistent with earlier studies that suggest occupational therapists working in non-traditional settings, and occupational therapy students in emerging role placements, remain true to the profession by adopting a more client-centred, occupational-focused approach (Clarke et al., 2015; Stickley and Hall, 2017).

Findings suggest there were some challenges retaining professional identity. These concerns are consistent with Turner's (2011) assertion that occupational therapists continue to struggle to identify and assert their identity and existing research that revealed misunderstandings about the roles of occupational therapists working in social enterprises and primary health promotion (Stickley and Hall, 2017; Wood, Fortune and McKinstry, 2013). This issue of professional identity may have implications for future practitioners and occupational therapy students working in diverse settings. Withers and Shann (2008) state that occupational therapists need to tackle these misunderstandings by confidently demonstrating the unique skills of the profession and by keeping occupation central to their practice. However, it could be argued the participants of this study successfully marketed themselves in an area dominated by sports professionals, by promoting the profession at sports conferences, 
collaborating with organisations and mentoring staff, and through demonstrating the value of occupation.

There is some evidence suggesting there are risks associated with taking on new roles or infringing upon roles that legitimately belong to other professionals (Letts, 2011). For example, Letts (2011) questions whether the activities of occupational therapists and physiotherapists overlap in stroke rehabilitation. The literature suggests the blurring of roles leads to the continued misunderstanding of what occupational therapists do and where the boundaries of their practice lie (Molineux and Baptiste, 2011). Molineux (2011) asserts that occupational therapists need to be clear about what they do and articulate the core philosophies of their profession and the boundaries of their practice. He emphasises that "occupation should permeate all that we do" (Molineux, 2011, p27), starting with the education of occupational therapy students through to occupational-focused practice, and that it should be the principal focus of research, in order to distinguish the role of occupational therapy from other professions.

Findings of this study demonstrate how the occupational therapy role was quite distinct from other professionals working to enable participation in sport. Using their dual training, holistic perspective and adopting an asset-based approach (RCOT, 2017) the participants ensured their clients were not seen from a disability perspective and emphasised their strengths and abilities to participate. In addition to demonstrating their unique skills by grading and adapting activities, the participants developed supportive partnerships with the sports sector and helped staff develop skills and awareness. By demonstrating the benefits of environmental adaptations, they provided more accessible and inclusive opportunities. These findings echo existing literature advocating for occupational therapists to educate other professions about grading activities, to alleviate prejudgements about an individual's level of performance, and offer disability-related training (Fairhurst, Bloom and Harvey, 2016; Sharp, Dunford and Seddon, 2012) in order to eliminate barriers and enhance opportunities for participation. This has implications for practice and supports Handcock and Tattersall's (2011) recommendations for occupational therapists to collaborate with graduate sports professionals to achieve increased activity levels within communities. There is also an 
opportunity here for interprofessional education in curriculums between health and sports science to enhance understanding of each other's roles and skills.

This study highlights opportunities for future practice and role emerging placements. Previous studies have shown that placing students in unconventional areas has increased awareness of the profession and the health and well-being benefits of occupation, as well as opening up opportunities for employment (Clarke et al., 2015). Literature suggests that role emerging placements enable students to develop a deeper affinity with the core philosophy of the profession and provides insights into alternative ways of working, potentially cultivating future innovators of diverse practices (Clarke et al., 2015). It is suggested, therefore, that Universities forge new partnerships with sports and leisure organisations and support expansion of the profession into this new terrain.

This study focuses on the experiences of occupational therapists based in the UK. Future research could explore the experiences of occupational therapists internationally, who are engaging people to participate in sport outside traditional settings, in order to gain a wider perspective. Additionally, qualitative research, which includes clients' perceptions of occupational therapy services in this setting would be beneficial.

\section{Limitations}

This study was limited by the small population size of occupational therapists working in diverse practices in the UK, and in the absence of a central database of information available to the researcher it was challenging to identify potential participants. Therefore, electronic snowballing was undertaken in an effort to extend the reach of the study and locate further participants. However, this approach resulted in responses from two participants who worked in the same organisation and led to similar data outcomes. Ethics did not allow for occupational therapists to be interviewed within the NHS / Social Care and as such the study excludes work that therapists may be doing to facilitate sport in these settings.

\section{Conclusion}


This appears to be the first study to explore the experiences of occupational therapists who enable people to participate in sport outside of traditional health and social care settings. As such it provides new insights that add to the existing debate and evidence base concerning the scope for occupational therapists to expand their practice into innovative settings and move towards a more occupation-focused approach. This paper illustrates that occupational therapists can play a significant role in sport, an area that is dominated by sports professionals. Therefore, it highlights opportunities for occupational therapists to be pioneering and develop new roles in response to the shifting healthcare landscape (RCOT, 2018).

\section{Key findings}

- The occupational lens used by occupational therapists clearly provides opportunities to increase engagement in physical activity and sport and address the nations inactivity problem.

- There are opportunities for occupational therapists to be innovative, by forging new paths into mainstream environments such as the sports and leisure industry.

\section{What the study has added}

This study highlights opportunities for occupational therapists to expand their practice into innovative settings, such as mainstream sport environments, and play a key role enabling people to participate in sport. 


\section{References}

Academy of Medical Royal Colleges (2015) Exercise: the miracle cure and the role of the doctor in promoting it (accessed 13 August 2020). Available at: http://www.aomrc.org.uk/wpcontent/uploads/2016/05/Exercise_the_Miracle_Cure_0215.pdf.

Box Positive (2019) Available at: https://boxpositive.co.uk/ (accessed 17 May 2019).

Braun V, Clarke V (2013) Successful Qualitative Research: A Practical Guide for Beginners. London: SAGE.

Clarke C, Martin M, Sadlo G, de-Visser R (2015) Facing Uncharted Waters: Challenges experienced by Occupational Therapy Students undertaking Role-emerging Placements. International Journal of Practice-based Learning in Health and Social Care Vol. 3 No 1 2015, pages 30-45.

Creek J (2014) Physical activity for mental health and well-being. In: Bryant W, Fieldhouse J, Bannigan K, et al. (eds) Creek's Occupational Therapy and Mental Health. Fifth edn: Churchill Livingstone, Edinburgh.

De Lyon, ATC; Neville, RD, Armour, KM (2017) The Role of Fitness Professionals in Public Health: A Review of the Literature. Quest, vol. 69, no. 3, pp. 313-330.

Department of Health (DoH) (2011) Chief Medical Officers - Start Active, Stay Active. A Report on Physical Activity for Health from the Four Home Countries' Chief Medical Officers. Department of Health London, UK, July.

Fairhurst KE, MA Bloom, GA, Harvey WJ (2017) The learning and mentoring experiences of Paralympic coaches. Disability and Health Journal, vol. 10, no. 2, pp. 240-246.

Finlay L (2006) Mapping Methodology. In: Finlay L, Ballinger C (eds). Qualitative Research for Allied Health Professionals: Challenging Choices. Chichester: John Wiley.

Green J, Thorogood N (2018) Qualitative methods for health research. Fourth edn, SAGE, Los Angeles.

Handcock P and Tattersall K (2012) Occupational Therapists Beware: Physical Activity Guidelines can Mislead, The British Journal of Occupational Therapy, vol. 75, no. 2, pp. 111-113.

Healthy Ireland, Department of Health (2016) Get Ireland Active! The National Physical Plan for Ireland. Available at: https://www.gov.ie/en/policy-information/b60202-nationalphysical-activity/ (accessed 12 September 2020). 
HM Government (2015) Sporting Future - A New Strategy for an Active Nation. Department for Digital, Culture, Media and Sport and Tracey Crouch MP, London, December.

Hunter EG, Gibson RW, Arbesman M, et al. (2017) Systematic Review of Occupational Therapy and Adult Cancer Rehabilitation: Part 1. Impact of Physical Activity and Symptom Management Interventions. The American journal of occupational therapy : official publication of the American Occupational Therapy Association 71(2).

Lee S, Waters F, Briffa K, et al. (2017) Limited interface between physiotherapy primary care and people with severe mental illness: a qualitative study. Journal of Physiotherapy, vol. 63, no. 3, pp. 168-174.

Letts LJ (2011) Optimal Positioning of Occupational Therapy. Canadian Journal of Occupational Therapy, vol. 78, no. 4, pp. 209-217.

Molineux M (2011) Standing Firm on Shifting Sands. New Zealand Journal of Occupational Therapy, vol. 58, no. 1, pp. 21-28.

Molineux M, Baptiste S (2011) Emerging occupational therapy practice: Building on the foundations and seizing the opportunities. In: M Thew, M Edwards, S Baptiste, M Molineux (eds) Role emerging occupational therapy: maximising occupation-focused practice. Wiley-Blackwell, Chichester.

Noble H, Smith J (2015) Issues of validity and reliability in qualitative research. Evidence Based Nursing, vol. 18 , no. 2, pp. 34-35.

Public Health England (2018) Physical inactivity: applying to All Our Health. Available at: https://www.gov.uk/government/publications/physical-activity-applyingall-our-health/physical-activity-applying-all-our-health (accessed 20 May 2019).

Royal College of Occupational Therapists (2018) Getting my life back: Occupational therapy promoting mental health and wellbeing in England. London: RCOT.

Royal College of Occupational Therapists (2019) Making personalised care a reality: The role of occupational therapy. London: RCOT.

Royal College of Occupational Therapists (2017) Professional Standards for Occupational Therapy Practice. London: RCOT.

Royal College of Occupational Therapists (2018) Strategic Intentions 2018-2023. London: RCOT.

Sense Rugby (2015) Available at: http://www.senserugby.com.au (accessed 26 August 2018). 
Sharp N, Dunford C, Seddon L (2012) A Critical Appraisal of How Occupational Therapists Can Enable Participation in Adaptive Physical Activity for Children and Young People. British Journal of Occupational Therapy, 75(11), 486-494. https://doi.org/10.4276/030802212X13522194759815.

Siegel P, Tencza M, Apodaca B, et al. (2017) Effectiveness of occupational therapy interventions for adults with rheumatoid arthritis: A systematic review. The American $\begin{array}{llll}\text { Journal of } & \text { Occupational }\end{array}$ doi:http://dx.doi.org.ezproxy.brighton.ac.uk/10.5014/ajot.2017.023176

Sport England (2017) Review of evidence on the outcomes of sport and physical activity: A rapid evidence review. Sport England, UK, May.

Sport New Zealand (2020) Every Body Active: Strategic Plan 2020 - 2024. Available at https://sportnz.org.nz/resources/every-body-active-strategic-plan-2020-2024/ (accessed 12 September 2020).

Stacey D, Hopkins M, Adamo K.B, et al. (2010) Knowledge translation to fitness trainers: a systematic review. Implementation science: IS, vol. 5, no. 1, pp. 28-28.

Stickley AJ, Hall KJ (2017) Social enterprise: a model of recovery and social inclusion for occupational therapy practice in the UK. Mental Health and Social Inclusion 21(2): 91101.

Taylor RR, Kielhofner G (2017) Kielhofner's research in occupational therapy: methods of inquiry for enhancing practice. Second edn, F.A. Davis Company, Philadelphia.

Turner A (2011) The Elizabeth Casson Memorial Lecture 2011: Occupational therapy - a profession in adolescence? British Journal of Occupational Therapy 74(7): 314-322.

University of Brighton Data Protection Policy Regulation (2018). Available at: https://staff.brighton.ac.uk/reg/legal/other/Data_Protection_Policy.pdf?_ga=2.1199 38763.211848725.1535574034-378269516.1431436205 (accessed 30 June 2018).

Wareham Y, Burkett B, Innes P, et al. (2018) Sport coaches' education, training and professional development: the perceptions and preferences of coaches of elite athletes with disability in Australia. Sport in Society, vol. 21, no. 12, pp. 2048-2067.

Whiteford G (2011) Occupational Deprivation: Understanding Limited Participation. In: Christiansen $C$ and Townsend EA (eds) Introduction to occupation: the art and science of living : new multidisciplinary perspectives for understanding human occupation as 
a central feature of individual experience and social organization, Upper Saddle River, N.J: Pearson.

Wilcock AA (2006) An occupational perspective of health. 2nd edn, SLACK Incorporated, Thorofare, N.J.

Wilcock AA, Hocking C (2015) An occupational perspective of health. Third Edn, Thorofare: SLACK.

Williams TL, Smith B, Papathomas A (2018) Physical activity promotion for people with spinal cord injury: physiotherapists' beliefs and actions. Disability and Rehabilitation, vol. 40, no. 1 , pp. 52-61.

Withers C, Shann S (2008) Embracing opportunities: Stepping out of the box. British Journal of Occupational Therapy, 71(3), pp.122-124.

Wood R, Fortune T, McKinstry C (2013) Perspectives of occupational therapists working in primary health promotion. Australian Occupational Therapy Journal, vol. 60, no. 3, pp. 161-170.

World Confederation for Physical Therapy. Available at https://www.wcpt.org/ (accessed 30 June 2019).

World Health Organization (2018) Global action plan on physical activity 2018-2030: more active people for a healthier world. Switzerland. World Health Organization. 